\title{
Genetic diversity of arsenic accumulation in rice and QTL analysis of methylated arsenic in rice grains
}

\author{
Masato Kuramata ${ }^{1 \dagger}$, Tadashi Abe $^{1 \dagger}$, Akira Kawasaki ${ }^{1}$, Kaworu Ebana $^{2}$, Taeko Shibaya ${ }^{3}$, Masahiro Yano ${ }^{3}$ \\ and Satoru Ishikawa ${ }^{1 *}$
}

\begin{abstract}
Background: Rice is a major source of dietary intake of arsenic (As) for the populations that consume rice as a staple food. Therefore, it is necessary to reduce the As concentration in rice to avoid the potential risk to human health. In this study, the genetic diversity in As accumulation and As speciation in rice grains was investigated using a world rice core collection (WRC) comprising 69 accessions grown over a 3-year period. Moreover, quantitative trait locus (QTL) analysis was conducted to identify QTLs controlling the dimethylarsinic acid (DMA) content of rice grains.

Results: There was a 3-fold difference in the grain As concentration of WRC. Concentrations of total-As, inorganic As, and DMA were significantly affected by genotype, year, and genotype-year interaction effects. Among the WRC accessions, Local Basmati and Tima (indica type) were identified as cultivars with the lowest stable total-As and inorganic As concentrations. Using an $F_{2}$ population derived from Padi Perak (a high-DMA accession) and Koshihikari (a low-DMA cultivar), we identified two QTLs on chromosome 6 (qDMAs6.1 and qDMAs6.2) and one QTL on chromosome 8 (qDMAs8) that were responsible for variations in the grain DMA concentration. Approximately 73\% of total phenotypic variance in DMA was explained by the three QTLs.
\end{abstract}

Conclusions: Based on the results provided, one strategy for developing rice cultivars with a low level of toxic As would be to change the proportion of organic As on the basis of a low level of total As content.

Keywords: Dimethylarsinic acid, Inorganic arsenic, QTL, World rice core collection

\section{Background}

Arsenic (As) exists in the natural environment and food in various chemical forms, which are mainly classified into two groups: organic As and inorganic As (iAs). Although iAs is more toxic than the organic, methylated species (Cullen and Reimer 1989), recent studies indicate that trivalent methylated arsenicals have higher cytotoxicity than pentavalent methylated arsenicals and iAs (Styblo et al. 2000; Markley and Herbert 2009). The concentrations and proportions of organic As and iAs varies depending on the food type (Signes-Pastor et al. 2008; EFSA 2009).

\footnotetext{
* Correspondence: isatoru@affrc.go.jp

${ }^{\dagger}$ Equal contributors

'Soil Environment Division, National Institute for Agro-Environmental

Sciences, 3-1-3 Kannondai, Tsukuba, Ibaraki 305-8604, Japan

Full list of author information is available at the end of the article
}

Rice is a major contributor to As intake in humans (Williams et al. 2005; Meharg et al. 2009; GilbertDiamond et al. 2011), because rice is mainly cultivated in anaerobic paddy soil, where arsenite $[\mathrm{As}(\mathrm{III})]$ is more available (Takahashi et al. 2004). The four main As species are found in rice grains are $\mathrm{As}(\mathrm{III})$, arsenate $[\mathrm{As}(\mathrm{V})]$, monomethylarsonic acid (MMA), and dimethylarsinic acid (DMA) (Williams et al. 2005). Arsenic species play a major role in determining the amount of As absorbed after consumption of As-contaminated rice. DMA in rice is poorly absorbed in vivo after oral administration, resulting in a low bioavailability in the human body. Conversely, iAs in rice are much more bioavailable than DMA, indicating a high potential risk to human health (Juhasz et al. 2006). The factors controlling the total As concentration and the proportions of As species in the

\section{实}


rice grain are complicated; genetics is a factor, because there is large variability in phenotypes among different rice cultivars (Norton et al. 2009b; Pillai et al. 2010; Norton et al. 2012). However, the genetic diversity in total-As and As species of rice germplasms is not fully understood, because previous studies used relatively small numbers of cultivar sets and cultivars with similar genetic backgrounds. A world rice core collection (WRC) comprising 69 accessions, which covers the genetic diversity of almost 32,000 accessions of Asian cultivated rice (Oryza sativa L.), has been developed to explore the genetic diversity of various traits (Kojima et al. 2005). Using the WRC, we found a large genotypic variation in grain $\mathrm{Cd}$ concentration (Uraguchi et al. 2009) and succeeded in identifying the quantitative trait loci (QTLs) controlling Cd accumulation in rice (Abe et al. 2011). Therefore, the WRC is a powerful tool for evaluating the genetic diversity in total As and As speciation in rice grains, and for further genetic analysis.

The selection of rice cultivars with low As is an effective approach for reducing the As contamination in rice. Moreover, information on the genetic control of As concentration in rice is required for the efficient breeding of commercial cultivars possessing both low-As and good agronomic traits. A previous study showed that QTLs related to total As in rice grains were found on chromosome 6 and 8 in a population derived from low- (cv. CJ06) and high-As accumulating cultivars (cv. TN1) (Zhang et al. 2008). Although both As(III) and methylated As (MMA and DMA) are taken up by the rice roots through the Lsi1 transporter of silicic acid ( $\mathrm{Si})(\mathrm{Ma}$ et al. 2008; Li et al. 2009), the dynamics of each As species in the plant body appears to be different (Carey et al. 2010; Kuramata et al. 2011). As far as we know, QTLs related to each As species in rice grains, especially DMA concentration, have not yet been studied.

The objectives of this study were 1) to evaluate the genetic diversity in total As and As speciation in rice grains of the WRC, and 2) to identify QTLs associated with the DMA concentration in rice. The exploitation of rice cultivars with a higher proportion of DMA than iAs would reduce the risk to human health.

\section{Results}

\section{Variation in grain As concentrations in WRC}

The WRC set, comprising 69 accessions, was cultivated in a paddy field with naturally abundant level of As. Some rice cultivars did not attain full maturity because of a delay in heading at the experimental site; therefore, only 58 rice cultivars were used in this study and were cultivated repeatedly across 3 years.

Two-way ANOVA indicated that total-As, iAs (sum of arsenite and arsenate), and DMA concentrations were significantly affected by genotype $(\mathrm{G})$, year $(\mathrm{Y})$, and $\mathrm{G} \times \mathrm{Y}$ factors
(Table 1). Total-As largely differed by $\mathrm{G}$ and $\mathrm{Y}$ factors, explaining 35.1 and $47.8 \%$ of the total variation, respectively. A similar trend was observed for iAs. A larger contribution of G (62.3\%) than Y (7.2\%) and G $\times$ Y (27.9\%) factors was found for the DMA concentration, indicating that the differences in grain DMA mostly depend on genotype.

The WRC ranking of total As concentrations in grains over 3 years are shown in Figure 1. Total grain As of WRC1 (a reference cultivar), japonica type cv. Nipponbare, varied over 3 years, i.e., $0.180 \mathrm{mg} \mathrm{kg}^{-1}$ for first year, $0.107 \mathrm{mg} \mathrm{kg}^{-1}$ for second year, and $0.206 \mathrm{mg} \mathrm{kg}^{-1}$ for third year (Additional file 1). To normalize the differences in total grain As concentrations among years, the ratio of the concentration of each genotype to WRC1 grown in the same year was used for the ranking. WRC42 (cv. Local Basmati) and WRC53 (cv. Tima) were categorized as the lowest total grain As cultivars: the ratio was approximately one-half that of WRC1. On the other hand, WRC13 (cv. Asu) and WRC40 (cv. Nepal 555) showed the highest As concentrations, with a ration 1.4-times higher than that of WRC1. A 3-fold difference in the total grain As concentration was observed between the lowest and highest WRC cultivars.

The genotypic variation of iAs is presented as the proportions of iAs to sums of iAs and DMA in the WRC grains (Figure 1, circles). The proportions of iAs ranged from $49.9 \%$ to $91.5 \%$ and iAs was the predominant As species in most cultivars. However, several cultivars presented lower ratios of iAs, around 50-60\%. WRC49, cv. Padi Perak, was a typical cultivar having a lower iAs ratio, although the total As concentration in the grains were similar to that of WRC1. This indicates that the DMA concentrations in the grains were higher in WRC49 than in WRC1 (Additional file 1). WRC42 and WRC53 showed the lowest total grain As and were also ranked as lower iAs cultivars.

Total As concentrations were positively correlated with iAs concentrations in the WRC grains grown in 2009 (Additional file 2; $p<0.001, r=0.909$ ). This trend was similar in $2007(p<0.001, r=0.823)$ and $2008(p<$ $0.001, r=0.615)$. On the other hand, the correlation coefficients between total As and DMA were smaller than those of total As and iAs, although statistically significant correlations were observed in 2007 ( $p<$ $0.005, r=0.385)$ and $2009(p<0.05, r=0.270)$, but not in $2008(p=0.702, r=-0.051)$.

\section{As accumulation in plants tissue among genotypes}

Total concentrations of As and the proportions of each As species in various plant tissues were compared among selected cultivars (WRC1, WRC13, WRC42, and WRC49) that differed in total As or DMA concentrations in their grains (Figure 2). In WRC1, the As concentration of the grain (brown rice) was the lowest, 
Table 1 Two-way ANOVA of As species in brown rice of WRC cultivars grown over a 3-year period in a paddy field under flooded conditions

\begin{tabular}{|c|c|c|c|c|c|c|c|}
\hline As species & Variation & SS & $d f$ & MS & $F$ & $P$ & $\mathrm{SSE} / \mathrm{SST}^{\mathrm{a}}(\%)$ \\
\hline \multirow[t]{4}{*}{ Total As } & $G$ & 0.4980 & 57 & 0.0087 & 56.72 & $<0.0001$ & 35.1 \\
\hline & Y & 0.6771 & 2 & 0.3386 & 2197.9 & $<0.0001$ & 47.8 \\
\hline & $G \times Y$ & 0.2160 & 114 & 0.0019 & 12.3 & $<0.0001$ & 15.2 \\
\hline & Error & 0.0268 & 174 & 0.0002 & & & \\
\hline \multirow[t]{4}{*}{ iAs } & G & 0.3641 & 57 & 0.0064 & 139.00 & $<0.0001$ & 42.0 \\
\hline & Y & 0.3113 & 2 & 0.1556 & 3387.4 & $<0.0001$ & 36.0 \\
\hline & $G \times Y$ & 0.1824 & 114 & 0.0016 & 34.83 & $<0.0001$ & 21.1 \\
\hline & Error & 0.0080 & 174 & 0.0000 & & & \\
\hline \multirow[t]{4}{*}{ DMA } & G & 0.0245 & 57 & 0.0004 & 74.93 & $<0.0001$ & 62.3 \\
\hline & Y & 0.0028 & 2 & 0.0014 & 247.7 & $<0.0001$ & 7.2 \\
\hline & $G \times Y$ & 0.0110 & 114 & 0.0001 & 16.77 & $<0.0001$ & 27.9 \\
\hline & Error & 0.0010 & 174 & 0.0000 & & & \\
\hline
\end{tabular}

Total As, total arsenic of grains; iAs, sum of As (III) and As (V); mAs, dimethylarsinic acid; G, Genotype; Y, year; G $\times$ Y, genotype-by-year interaction.

a Sum of squares (SS) of each effect by total SS.

followed by that of the husk. Arsenic accumulated at the highest levels in upper leaf blades and increased with increasing internode number. The As level of the rachis was slightly higher than that of the leaf sheathes. Similar distribution patterns of As accumulation were observed in other selected rice cultivars. All plant parts of WRC42 (a low-As accumulating accession) showed lower As concentrations than the corresponding parts of WRC1. On the other hand, higher As concentrations in the upper leaf blades, rachis, husk, and brown rice were observed in a high-As accumulating cultivar, WRC13. WRC42 and WRC49 had lower proportions of iAs in their grains than WRC1, whereas iAs was present in high proportions in other plant parts.

\section{QTL analysis for DMA concentrations of rice grains}

The QTLs responsible for DMA concentrations in rice grains were investigated. One parental cultivar, Koshihikari,

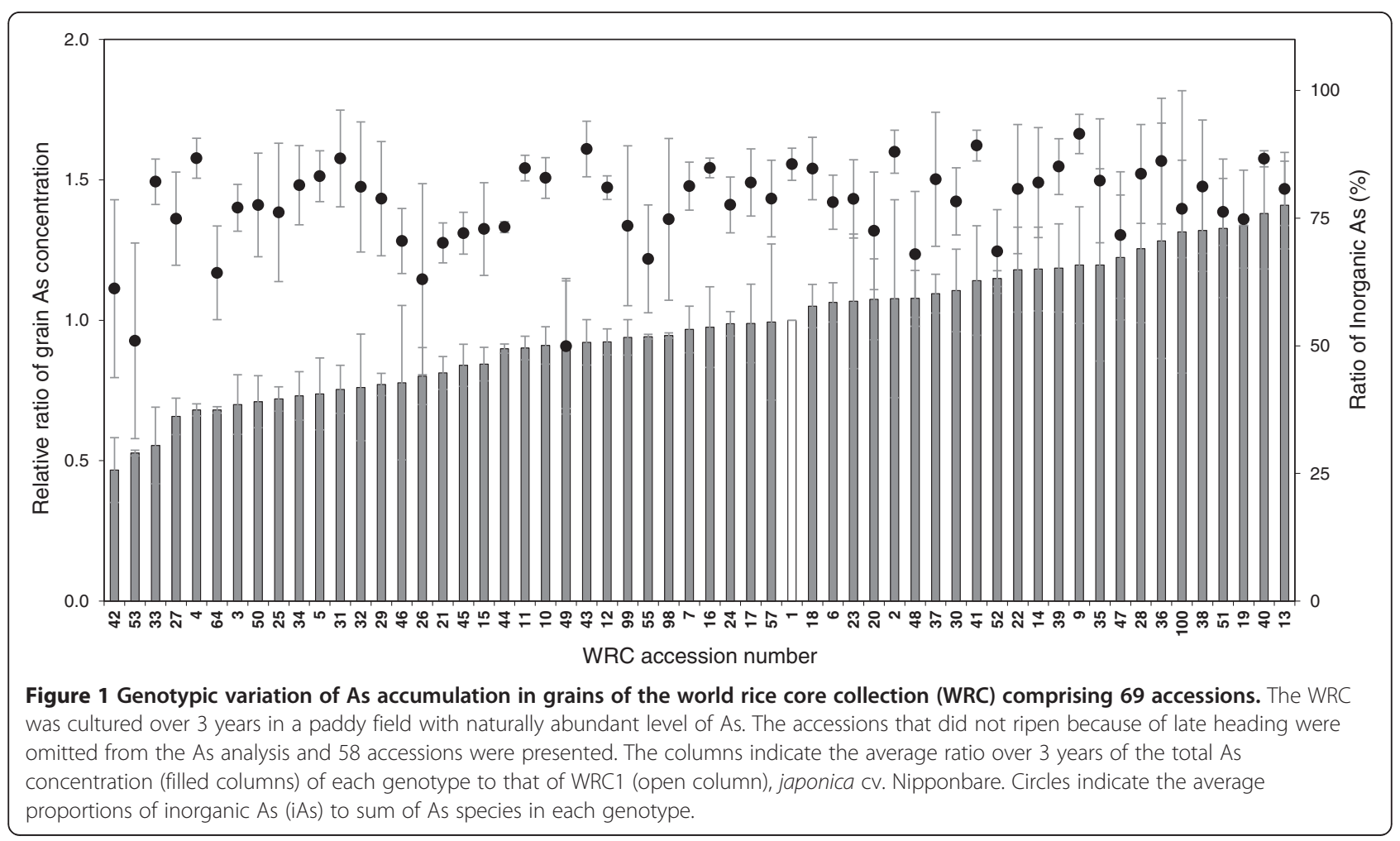




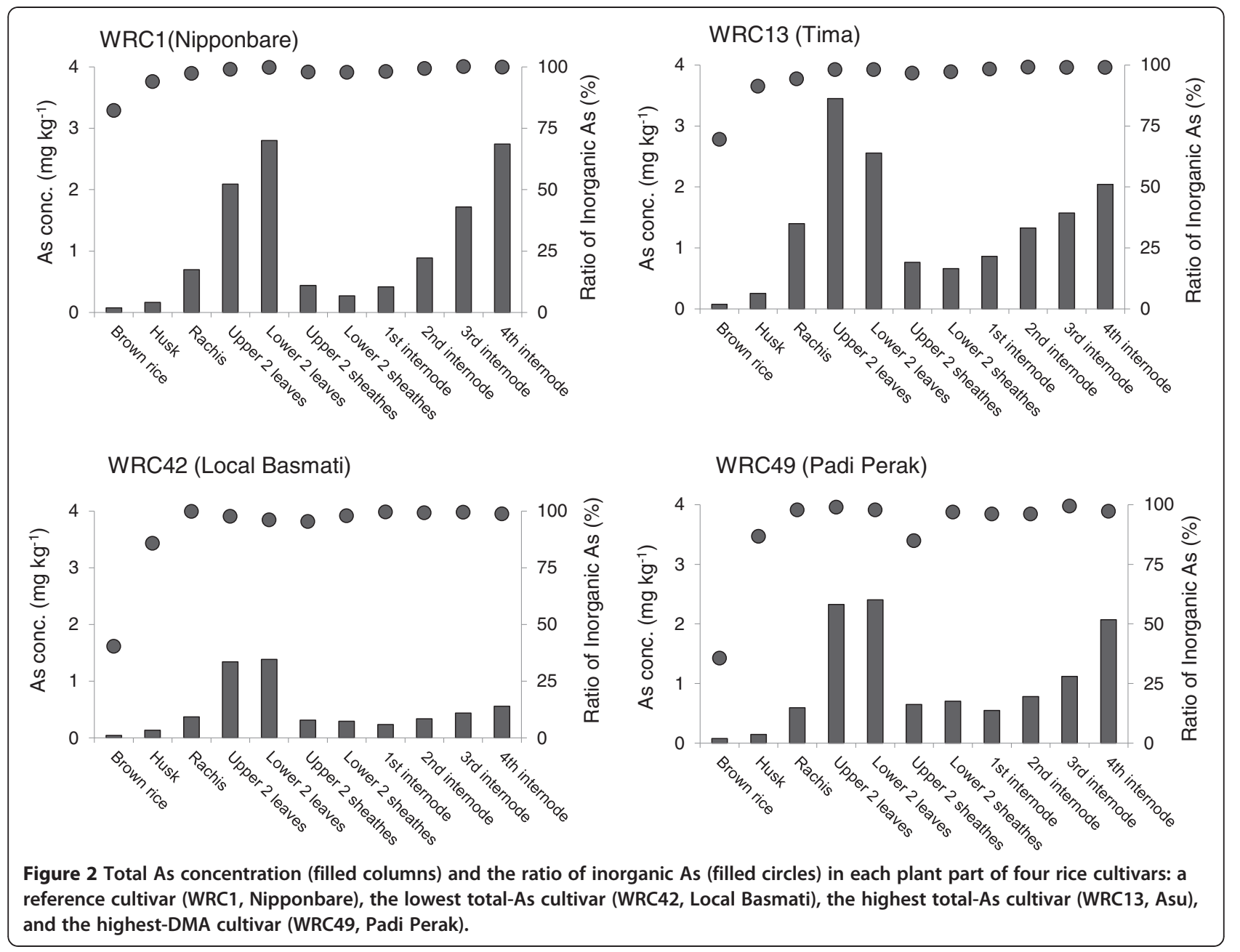

was identical to WRC1 Nipponbare in terms of As concentrations; the iAs concentration was higher than the DMA concentration in the grains (Figure $3 \mathrm{~A}$ ) and the concentrations were $0.155 \mathrm{mg} \mathrm{kg}^{-1}$ for iAs and $0.027 \mathrm{mg} \mathrm{kg}^{-1}$ for DMA. By contrast, the other parent, WRC49 (Padi Perak), showed $0.106 \mathrm{mg} \mathrm{kg}^{-1}$ for iAs and $0.074 \mathrm{mg} \mathrm{kg}^{-1}$ for DMA. Thus, Padi Perak had a higher grain DMA concentration than Koshihikari. The average concentrations of iAs and DMA in the $F_{2}$ population were $0.120 \mathrm{mg} \mathrm{kg}^{-1}$ and 0.051 $\mathrm{mg} \mathrm{kg}^{-1}$, respectively, and their values lay between the parental cultivars. A wide and continuous variation in the grain DMA concentrations $\left(0.041-0.351 \mathrm{mg} \mathrm{kg}^{-1}\right)$ was observed in the $\mathrm{F}_{2}$ population (Figure $3 \mathrm{~B}$ ).

Three QTLs related to the grain DMA concentrations were identified. A summary of the QTL analysis and the chromosomal locations of the QTLs are shown in Table 2 and Figure 4, respectively. Two QTLs were detected on the short arm of chromosome 6 and were designated tentatively as $q D M A s 6.1$ and $q D M A s 6.2$. The other QTL was located on chromosome 8 and designated tentatively as qDMAs8. All QTLs increased the grain DMA concentration, with the additive effects coming from the Padi Perak allele. Approximately $73 \%$ of the phenotypic variance was explained by the three QTLs, and qDMAs6.1, on chromosome 6 accounted for $36 \%$ of the variance.

\section{Discussion}

In this study, we found that all the factors studied (genotype, year, and genotype by year interaction) affected total-As, iAs, and DMA concentrations in the WRC rice grains (Table 1). Similar findings were reported by (Pillai et al. 2010), who compared total-As and As species concentration in the grains of approximately 20 rice cultivars grown across 3 -years on a flooded paddy field with a moderate As concentration. Relatively large percentages of year-variations compared with the total variations were observed in total-As and iAs concentrations, 47.8 and $36.0 \%$, respectively, even though all the WRC accessions were grown in the same field across 3 years. The concentrations of total-As and iAs in the all WRC grains were significantly lower in 2008 than in 2007 and 

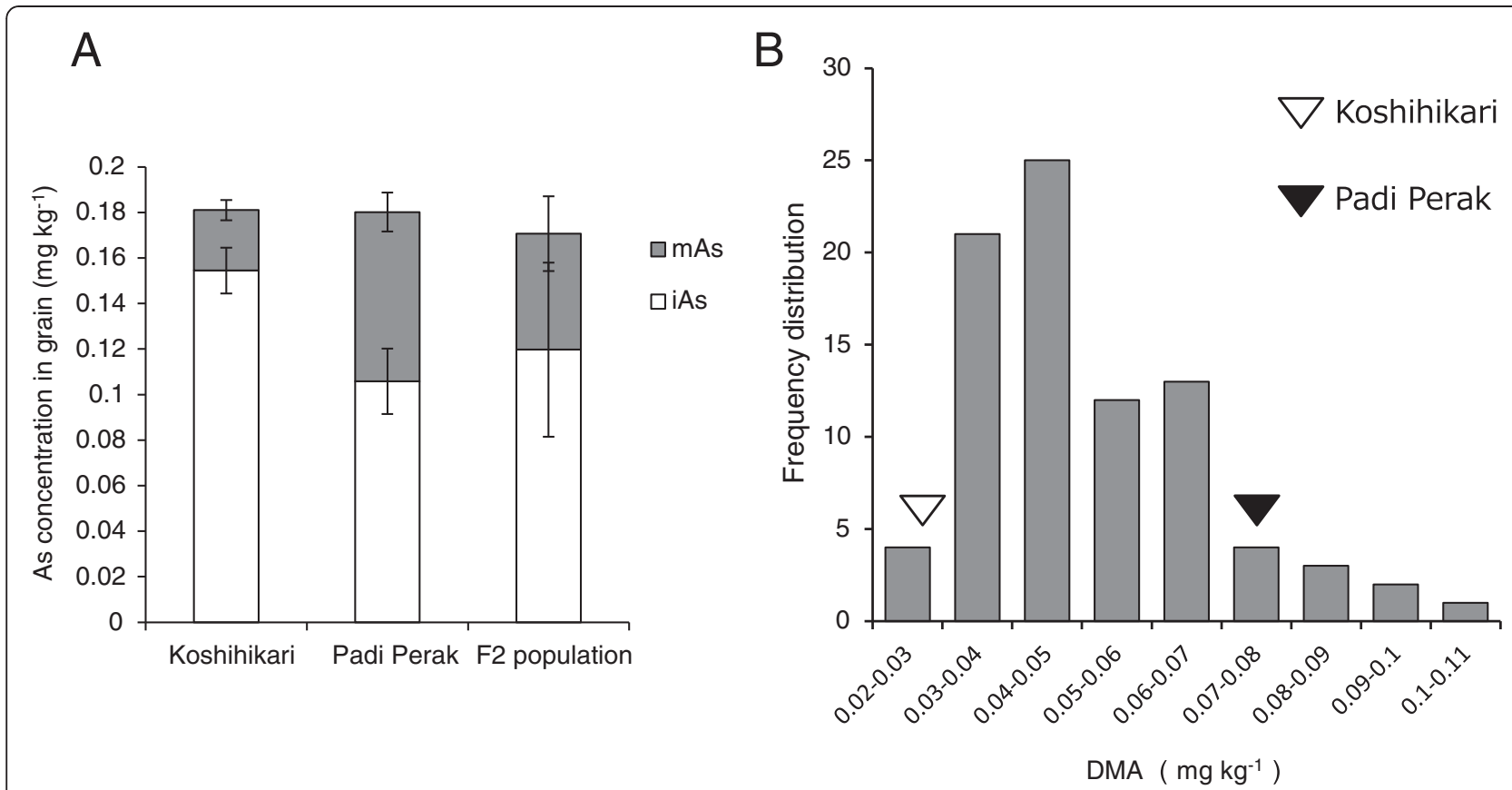

Figure 3 As concentration in Koshihikari, Padi Perak, and an $\mathbf{F}_{\mathbf{2}}$ population. (A) Average concentrations of inorganic As (iAs) and DMA in grains. (B) Frequency distribution for the grain DMA concentrations in the $F_{2}$ population. Black and white arrows indicate the means of Padi Perak and Koshihikari, respectively.

in 2009 (Additional file 1). The delay of transplanting the plants into the paddy field in 2008 might have affected their As concentrations, especially for iAs, which is the major species in total-As, and resulted in some inconsistency in rankings of cultivars for As concentrations among years. On the other hand, annual differences in DMA concentrations of the WRC grains were small, and the variation was largely attributable to genetics. Therefore, these results indicate that the DMA concentration in the rice grain could be modified through genetic analysis and plant breeding.

A 3-fold difference in the total As of rice grains in the WRC was found (Figure 1). Our previous report showed that there was a 67 -fold difference in the grain $\mathrm{Cd}$ concentration in the same WRC accessions grown in the same field used in this study (Uraguchi et al. 2009). The screening results indicated that the genetic diversity of the grain As concentration is not as wide as grain $\mathrm{Cd}$ concentrations. In addition, previous reports suggested that the rankings of rice cultivars for total grain As concentrations vary greatly across environments (Norton et al. 2009a; Ahmed et al. 2011), indicating the difficulty of genotype selection for lowering rice grain As concentration. Although we did not confirm the genotypic variation in the WRC grain As concentrations across different sites, two cultivars, WRC42 (Local Basmati) and WRC53 (Tima), showed the lowest concentrations of total-As and iAs in their grains and the concentrations were stably low across the 3 years (Figure 1 and Additional file 1). A cultivar, BR3, adapted for the boro rice season was identified as showing a stable low grain As by two papers, independently (Norton et al. 2009b; Ahmed et al. 2011); the ratios of grain As concentrations of BR3 to that of Nipponbare were 0.58 and 0.66 when their cultivars were grown on two sites in Bangladesh (Norton et al. 2009b). In this study, the ratio to Nipponbare was 0.46 for Local Basmati and 0.53 for Tima, suggesting that the two cultivars have an equivalent or

Table 2 Quantitative trait loci (QTLs) for grain DMA concentration in the $F_{2}$ population

\begin{tabular}{lllllll}
\hline Trait & QTL $^{\mathbf{a}}$ & Chromosome & Nearest maker & LOD $^{\mathbf{b}}$ & Additive effect $^{\mathbf{2}^{\mathbf{d}}}$ \\
\hline Grain DMA concentration & qDMAs6.1 & 6 & AE060000003 & 11.06 & -0.014 & 0.36 \\
& qDMAs6.2 & 6 & AE06001721 & 6.90 & -0.007 & 0.25 \\
& qDMAs8 & 8 & AE08000162 & 3.89 & -0.0089 & 0.12 \\
\hline
\end{tabular}

\footnotetext{
${ }^{a}$ Individual QTLs are shown in italics as the abbreviation of the trait and the chromosome number.

${ }^{b}$ After 1000-permutation tests, the threshold value of the logarithm of odds (LOD) was calculated as 3.88 .

${ }^{c} A$ negative value of the additive effect indicates that the allele from Padi Perak increased the phenotypic value.

${ }^{d} r^{2}$ represents the proportion of the phenotypic variance explained by the QTL.
} 


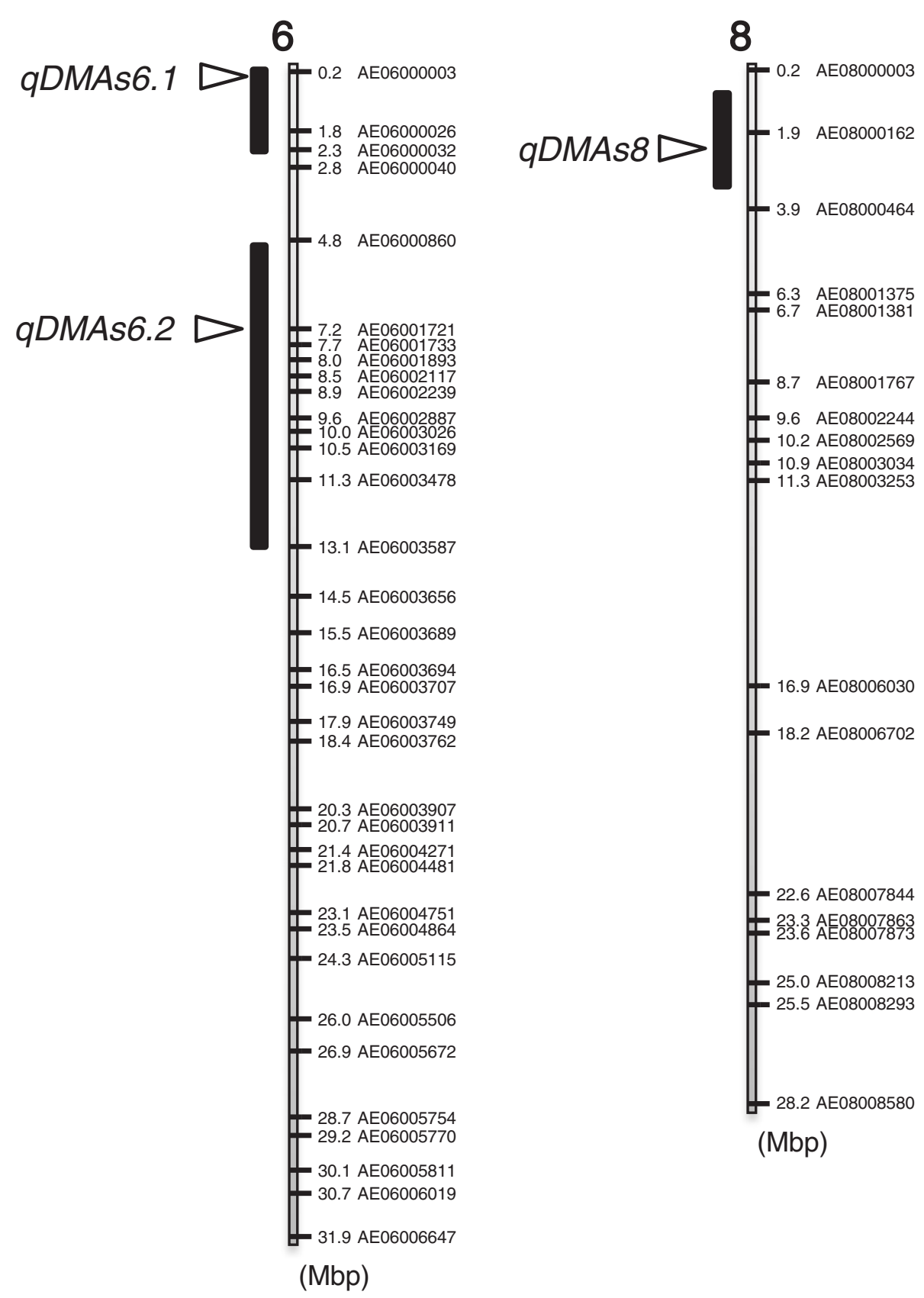

Figure 4 SNP linkage map showing locations of QTLs related to grain DMA concentration. Chromosome numbers are indicated above and SNP marker names and physical distance (Mbp) from the distal end of the short arm of each chromosome are shown. The bars and triangle symbols represent chromosome regions exceeding a threshold logarithm of odds (LOD, 3.88) value for the trait, according to a 1000-permutation test and LOD peaks of putative QTLs, respectively.

superior ability for reducing grain their As concentrations to that of BR3.

It has been suggested that differences in days to heading $(\mathrm{DTH})$ may be associated with the genotypic variation in grain As concentrations (Pillai et al. 2010). In this study, no correlation between the DTH and total grain As concentrations was found among the WRC accessions $(r=-0.025, p=0.853$ in 2007, $r=-0.222$, $p=0.094$ in 2008, and $r=-0.124, p=0.355$ in 2009). However, DTH was longer for the low-As cultivars Local Basmati and Tima than for the Nipponbare; differences of approximately 20 days were observed. The ears of low-As cultivars appeared when the temperature gradually decreased at the experimental site, and a relatively lower temperature during heading to maturing could have influenced As transport into their grains. Further 
investigation is needed to determine the effect of DTH on grain As concentration in rice.

The As concentrations of Local Basmati was the lowest, not only in the grains, but also in other shoot parts (Figure 2). On the other hand, cv. Asu had the highest values for all plant parts. iAs is a major species in all shoot parts; therefore, the differences in total As observed in all plant parts between the cultivars could be explained by the difference in root iAs uptake and/or translocation of iAs from roots to shoots. As(III), the dominant As species in the anaerobic paddy soil, is taken up by rice roots principally through the Lsi1 transporter, which is responsible for Si uptake (Ma et al. 2008). In addition, the dynamics of As (III) and $\mathrm{Si}$ in the plant body after root uptake might be similar, because the highest concentrations and amounts of As (Figure 2) and Si (Ma et al. 1989) were found in leaf blades in rice. Although iAs was also the dominant species in rice grains of the WRC, the proportions were not in accordance with those observed in other plant parts. DMA accumulated specifically in the grains, and Padi Perak had the highest DMA concentrations and the lowest proportions of iAs in its grains (Figure 1 and Additional file 1). This trend was stable across 3 years, so this cultivar is likely to have a specific ability to accumulate DMA in the grain.

The results of QTL analysis revealed that $q D M A s 6.1$ and $q D M A s 6.2$, on chromosome 6 and $q D M A s 8$ on chromosome 8 were responsible for increasing the grain DMA concentration and all of these alleles were inherited from Padi Perak (Table 2 and Figure 4). (Zhang et al. 2008) also identified two QTLs for total grain As concentrations on chromosome 6 and 8. The QTLs were located at 19-24 Mbp on chromosome 6 and at 4.8-5.1 Mbp on chromosome 8 in physical distance (Gramene, http://www.gramene.org/). These QTL positions are different to those identified in the present study. (Norton et al. 2010) found several QTLs for total As concentrations in rice leaves and a QTL, qAs6.1, near marker RM253 was located within our QTL region between AE06000860 and AE06003587. MMA and DMA are also taken up by rice roots through the rice aquaporin Lsi1 (OsNIP2;1) transporter (Li et al. 2009). However, the differences in grain DMA concentrations between Padi Perak and Koshihikari are not likely to be directly associated with this transporter, because the Lsi1 gene (Os02g0745100) is located on chromosome 2. Conversely, qDMAs6.2 contains the Lsi6 (OsNIP2;2) gene, which encodes an Si transporter related to inter-vascular transfer in the nodes of rice plants and is a homolog of the Lsilgene (Yamaji and Ma 2009). Although Lsi6 can also mediate arsenite transport when expressed in Xenopus oocytes, knockout lines of Lsi6 did not show decreased As concentrations in their shoots and roots compared with the wild-type (Ma et al. 2008). This may be the result of assaying As at the seedling stage; Lsi6 is specifically expressed in the node I below panicles after the grain filling stage (Yamaji and Ma 2009). If Lsi6 in node I is permeable to methylated As species MMA and DMA, like Lsi1 in the roots, differences in grain DMA concentration in rice cultivars may be caused by a differential transport function of Lsi6 or a differential expression of the Lsi6 gene. In excised panicles, high mobility of DMA in the xylem and phloem, and specific unloading of DMA into the grain, has been reported by (Carey et al. 2010).

Several researchers have observed that As methylation may not occur in planta, because methylated As species were not found in plants exposed to iAs under axenic conditions (Jia et al. 2012; Lomax et al. 2012). In addition, there was no further methylation in rice plants exposed to MMA or DMA under axenic conditions (Jia et al. 2012). These results suggest that methylated As species present in rice plants are derived from the soil through microorganism-mediated methylation. The microarray-based GeoChip analysis of microbial genes revealed that a methyltransferase gene, $\operatorname{ars} M$, was abundant in a Bangladeshi paddy soil containing a high As level (34 $\left.\mathrm{mg} \mathrm{kg}^{-1}\right)$, suggesting that DMA is produced by specific soil microbes (Lomax et al. 2012). The abundance of root exudates stimulates microbial growth and attracts more soil microorganisms to the root surface (Marschner et al. 2011). The density and activity of microbes carrying the ars $M$ gene may differ in the root surfaces among rice cultivars. In addition, the genotypic variation in As accumulation and speciation in rice could be influenced by the differential rates of radial oxygen loss from their roots (Wu et al. 2011). Thus, the events that occur in the rhizosphere are important factors for As accumulation and speciation. It is also possible that the detected QTLs are linked to rhizosphere methylation, which is associated with root biology, such as root exudation or root oxidation. In the future, fine mapping is needed to identify the genes related to grain DMA accumulation and functional analysis will also be required to understand the physiological role of the QTL genes.

\section{Conclusions}

The exploitation of rice cultivars that can accumulate less iAs in the grain is a promising technology for reducing As contamination in rice. We found a unique rice cultivar showing a high proportion of DMA in the grain from the WRC and identified several QTLs controlling rice DMA concentration. This cultivar could be used as a starting material to produce new cultivars with a lower iAs ratio through DNA marker assisted selection.

\section{Methods}

\section{Plant materials and field experiments}

The WRC seeds, comprising 69 cultivars, were obtained from the Genebank of the National Institute of Agrobiological 
Sciences (URL: http://www.gene.affrc.go.jp/databases-core collections_wr_en.php). To observe the segregation patterns of grain DMA concentrations in $F_{2}$ populations, $F_{2}$ seeds were obtained by crossing a high-DMA accumulating cultivar WRC 49 (cv. Padi Perak) and a low-DMA accumulating cultivar Koshihikari. The Padi Perak and Koshihikari cultivars are categorized as tropical japonica and temperate japonica types, respectively. To evaluate the As accumulation and speciation in the grain, the WRC was grown over 3 years (2007, 2008, and 2009) on the same paddy field and the $F_{2}$ population was grown in 2010 following the WRC cultivation. The paddy soil was classified as an alluvial soil; the As concentration was 1.4 $\mathrm{mg} \mathrm{kg}{ }^{-1}$ dry weight, as determined by $1 \mathrm{M} \mathrm{HCl}$ extraction in accordance with the Agricultural Land Soil Pollution Prevention Law of Japan.

Surface sterilized seeds of the 69 accessions and the $F_{2}$ population were germinated and grown in nursery boxes filled with artificially prepared fertilized soil (Ponzol No.1; Sumitomo Chemical Co., Ltd., Tokyo, Japan). The field site was an experimental paddy field at the National Institute for Agro-Environmental Sciences (latitude 36 01'32.31" N, longitude 104 06' 23.88” E, altitude $21 \mathrm{~m}$ ) in Tsukuba, Japan. Seedlings (1-month-old) of the WRC were transplanted into the flooded paddy field with a single plant per hill, spaced at $15 \times 30 \mathrm{~cm}$ and 12 plants of each cultivar were planted per row, in the middle May in 2007 and 2009 and in early in June in 2008. For the $\mathrm{F}_{2}$ population, 100 seedlings were transplanted into the field in the same manner as the WRC, in 2010. A commercial chemical fertilizer was applied at the rate of $50 \mathrm{~kg}-\mathrm{N} \mathrm{ha}{ }^{-1}, 50 \mathrm{~kg}-\mathrm{P} \mathrm{ha}{ }^{-1}$, and $50 \mathrm{~kg}-\mathrm{K} \mathrm{ha}^{-1}$ as a base or $20 \mathrm{~kg}-\mathrm{N} \mathrm{ha}{ }^{-1}$ as a side dressing, respectively. Surface irrigation was applied before the mid-season drainage was done for about 1 week in early in July, then a full irrigation condition was applied again until grain harvesting. The central two plants in each row of the WRC were collected for As analysis. All plants of the $\mathrm{F}_{2}$ population that reached maturity were harvested.

\section{Sample preparation for As analysis and speciation}

After threshing, rice grains in the WRC and $F_{2}$ individuals were dehusked to obtain brown rice and then ground to a fine powder through $0.5-\mathrm{mm}$ mesh using a stainless steel rotor mill (P-14, Fritsch, Kastl, Germany). For several cultivars showing low- and high-As concentrations in their grains (WRC1, WRC13, WRC42, and WRC49), the mature plants were divided into 11 plant parts: brown rice, husk, rachis, upper leaf blades (including flag leaf), lower leaf blades, upper leaf sheaths, lower leaf sheaths, and the first to fourth internodes of culms. These parts were also ground to a fine powder. Powdered sample $(0.5 \mathrm{~g})$ was digested in $65 \mathrm{~mL}$ polypropylene tubes (DigiTUBEs, GL Science, Tokyo, Japan) with a $5 \mathrm{~mL}$ of an acid mixture comprising high-grade concentrated $\mathrm{HNO}_{3}$ and $\mathrm{H}_{2} \mathrm{O}_{2}$ (5:1, v/v) using the heating block system (Digi-PREP LS, SPS SCIENCE, Canada) at $105^{\circ} \mathrm{C}$ for $3 \mathrm{hrs}$. The digested solution was filtered using disposable 0.2- $\mu \mathrm{m}$ PTFE syringe filters after appropriate dilution with Milli-Q water. Two certified standard materials, NIST SRM 1568a rice flour (National Institute of Standards and Technology, Gaithersburg, USA) and NMIJ CRM 7503a rice flour (National Metrology Institute of Japan, Tsukuba, Japan), was used to ensure the precision of the analytical procedure.

To determine As species in grains and shoots, a powdered sample $(0.2 \mathrm{~g}$ dry weight) was mixed with $1 \mathrm{~mL}$ of $0.15 \mathrm{M} \mathrm{HNO}_{3}$ in a $15 \mathrm{~mL}$ polyethylene tube, and the mixture was heated on an aluminum heating block at $80^{\circ} \mathrm{C}$ for $2 \mathrm{hrs}$. The solution obtained was diluted to 5 $\mathrm{mL}$ with Milli-Q water and passed through a $0.2-\mu \mathrm{m}$ PTFE syringe filter before analysis.

\section{Total As determination and speciation analysis}

The concentrations of total As in grains and shoots were determined using inductively coupled plasma mass spectroscopy (ICP-MS, ELAN DRC-e, Perkin-Elmer Sciex, DE). Separation of As(III), As(V), MMA(V), and DMA(V) was performed by HPLC (PU 712i, GL Science, Tokyo, Japan) on a reversed phase ODS-3 column (Kuramata et al. 2011). The solution was eluted from the column and directly introduced to the ICP-MS and the arsenic signal (m/z 75) was monitored. The rice grains of our samples contained mostly As(III) and DMA(V), with trace amounts of MMA (V) and $\mathrm{As}(\mathrm{V})$. In this paper, the sum of As(III) and As (V) is presented as total inorganic As (iAs), because the $\mathrm{HNO}_{3}$ used in sample preparation generally acts as an oxidative acid (Arao et al. 2009). Moreover, MMA was only detected in a few samples at the detection limit (0.02 $\mathrm{mg} \mathrm{kg}^{-1}$ ); therefore, only DMA concentration was shown as methylated As.

\section{Genotyping by single-nucleotide polymorphism (SNP) markers}

The DNA was extracted from a piece of leaf blade of the parental cultivars and $F_{2}$ individuals. The 307 SNPs used for the genotyping of the $F_{2}$ population were selected from a 768-plex SNPs set, which was derived from a comparison of whole-genome sequencing between Nipponbare and Khau Mac Kho. SNPs were detected using the GoldenGate BeadArray technology platform and BeadStation 500G system (Illumina, San Diego, CA, USA), according to the manufacturer's instructions. The SNP markers used in the $F_{2}$ population are shown in Additional files 3 and 4.

\section{Construction of linkage map and QTL analysis}

We constructed the linkage map using MAPMAKER/EXP 3.0 (Lander et al. 1987). QTL analysis was performed using composite interval mapping, as implemented by the Zmapqtl program (model 6) provided by QTL Cartographer 
version 2.5 (http://statgen.ncsu.edu/qtlcart/). Genome-wide threshold values $(\alpha=0.05)$ were used to detect putative QTLs, based on the results of 1000 permutations (Churchill and Doerge 1994).

\section{Statistical analysis}

Expected genotypic variance (G), annually environmental variance $(\mathrm{E})$, and $\mathrm{G} \times \mathrm{E}$ interaction were estimated by two-way ANOVA using the IBM SPSS Statistics package (IBM Japan, Tokyo). The percentage variation explained by each source of variation was calculated for the sum of squares of each effect by total sum of squares, according to the report of (Pillai et al. 2010).

\section{Additional files}

Additional file 1: Inorganic As (iAs), DMA, and total As (tAs) concentrations in the grains of 58 cultivars grown for 3 years.

Additional file 2: Correlation of total As and each the concentration of each As species in unpolished grains of WRC grown in 2009: filled square, inorganic As $(r=0.909, \mathrm{n}=58, p<0.001)$; open circle, DMA $(r=0.270, \mathrm{n}=58, p<0.05)$.

Additional file 3: List of 307 SNPs used for genotyping of the $F_{2}$ population derived from a cross between Koshihikari and Padi Perak.

Additional file 4: Physical map constructed using 307 SNP markers.

\section{Competing interests}

The authors declare that they have no competing interests.

\section{Authors' contributions}

MK and TA designed the research and carried out all the experiments. AK analyzed the As by ICP-MS. KE provided the core rice collection and performed the SNP analysis. TS performed the genotyping of the mapping population. MY designed the research and provided the $\mathrm{F}_{2}$ seeds. SI designed the research and wrote the manuscript. All authors discussed the results and commented on the manuscript. All authors read and approved the final manuscript.

\section{Acknowledgements \\ This work was supported by a grant from the Ministry of Agriculture, Forestry, and Fisheries of Japan (research project for ensuring food safety from farm to table AC-1121). The world rice core collection was kindly supplied by the Genebank at the National Institute of Agro-biological Sciences in Japan. We are very grateful to K. Abe, H. Yamaguchi, and T. Ara, at the National Institute for Agro-Environmental Sciences (NIAES), for their expert field assistance, and H. Tanikawa, E. Saka, and Y. Nagaosa (NIAES) for their laboratory assistance.}

\section{Author details \\ 1 Soil Environment Division, National Institute for Agro-Environmental Sciences, 3-1-3 Kannondai, Tsukuba, Ibaraki 305-8604, Japan. ${ }^{2}$ Genetic Resources Center, National Institute of Agrobiological Sciences, 2-1-2 Kannondai, Tsukuba, Ibaraki 305-8602, Japan. ${ }^{3}$ Agrogenomics Research Center, National Institute of Agrobiological Sciences, 2-1-2 Kannondai, Tsukuba, Ibaraki 305-8602, Japan.}

Received: 18 July 2012 Accepted: 28 December 2012 Published: 11 January 2013

\section{References}

Abe T, Taguchi-Shiobara F, Kojima Y, Ebitani T, Kuramata M, Yamamoto T, Yano M, Ishikawa S (2011) Detection of a QTL for accumulating Cd in rice that enables efficient Cd phytoextraction from soil. Breed Sci 61:43-51
Ahmed ZU, Panaullah GM, Gauch H, McCouch SR, Tyagi W, Kabir MS, Duxbury JM (2011) Genotype and environment effects on rice (Oryza sativa L.) grain arsenic concentration in Bangladesh. Plant Soil 338:367-382

Arao T, Kawasaki A, Baba K, Mori S, Matsumoto S (2009) Effects of water management on cadmium and arsenic accumulation and dimethylarsinic acid concentrations in Japanese rice. Environ Sci Technol 43:9361-9367

Carey AM, Scheckel KG, Lombi E, Newville M, Choi Y, Norton GJ, Charnock JM, Feldmann J, Price AH, Meharg AA (2010) Grain unloading of arsenic species in rice. Plant Physiol 152:309-319

Churchill GA, Doerge RW (1994) Empirical threshold values for quantitative trait mapping. Genetics 138:963-971

Cullen WR, Reimer KJ (1989) Arsenic speciation in the environment. Chem Rev 89:713-764

EFSA (2009) Scientific opinion on arsenic in food. EFSA panel on contaminants in the food chain (CONTAM). EFSA Journal 7:1351

Gilbert-Diamond D, Cottingham KL, Gruber JF, Punshon T, Sayarath V, Gandolfi AJ, Baker ER, Jackson BP, Folt CL, Karagas MR (2011) Rice consumption contributes to arsenic exposure in US women. Proc Natl Acad Sci USA 108:20656-20660

Jia Y, Huang H, Sun GX, Zhao FJ, Zhu YG (2012) Pathways and Relative Contributions to Arsenic Volatilization from Rice Plants and Paddy Soil. Environ Sci Technol 46:8090-8096

Juhasz AL, Smith E, Weber J, Rees M, Rofe A, Kuchel T, Sansom L, Naidu R (2006) In vivo assessment of arsenic bioavailability in rice and its significance for human health risk assessment. Environ Health Perspect 114:1826-1831

Kojima Y, Ebana K, Fukuoka S, Nagamine T, Kawase M (2005) Development of an RFLP-based rice diversity research set of germplasm. Breed Sci 55:431-440

Kuramata M, Abe T, Matsumoto S, Ishikawa S (2011) Arsenic accumulation and speciation in Japanese paddy rice cultivars. Soil Sci Plant Nutr 57:248-258

Lander ES, Green P, Abrahamson J, Barlow A, Daly MJ, Lincoln SE, Newberg LA (1987) MAPMAKER: an interactive computer package for constructing primary genetic linkage maps of experimental and natural populations. Genomics 1:174-181

Li RY, Ago Y, Liu WJ, Mitani N, Feldmann J, McGrath SP, Ma JF, Zhao FJ (2009) The Rice Aquaporin Lsi1 mediates uptake of methylated arsenic species. Plant Physiol 150:2071-2080

Lomax C, Liu WJ, Wu LY, Xue K, Xiong JB, Zhou JZ, McGrath SP, Meharg AA, Miller AJ (2012) Methylated arsenic species in plants originate from soil microorganisms. New Phytol 193:665-672

Ma JF, Nishimura K, Takahashi E (1989) Effect of silicon on the growth of rice plant at different growth-stages. Soil Sci Plant Nutr 35:347-356

Ma JF, Yamaji N, Mitani N, Xu XY, Su YH, McGrath SP, Zhao FJ (2008) Transporters of arsenite in rice and their role in arsenic accumulation in rice grain. Proc Natl Acad Sci USA 105:9931-9935

Markley CT, Herbert BE (2009) Arsenic Risk Assessment: The importance of speciation in different hydrologic systems. Water Air Soil Poll 204:385-398

Marschner P, Crowley D, Rengel Z (2011) Rhizosphere interactions between microorganisms and plants govern iron and phosphorus acquisition along the root axis - model and research methods. Soil Biol Biochem 43:883-894

Meharg AA, Williams PN, Adomako E, Lawgali YY, Deacon C, Villada A, Cambell RCJ, Sun G, Zhu YG, Feldmann J, Raab A, Zhao FJ, Islam R, Hossain S, Yanai J (2009) Geographical variation in total and inorganic arsenic content of polished (white) rice. Environ Sci Technol 43:1612-1617

Norton GJ, Deacon CM, Xiong LZ, Huang SY, Meharg AA, Price AH (2010) Genetic mapping of the rice ionome in leaves and grain: identification of QTLs for 17 elements including arsenic, cadmium, iron and selenium. Plant Soil 329:139-153

Norton GJ, Duan GL, Dasgupta T, Islam MR, Lei M, Zhu YG, Deacon CM, Moran AC, Islam S, Zhao FJ, Stroud JL, McGrath SP, Feldmann J, Price AH, Meharg AA (2009a) Environmental and genetic control of arsenic accumulation and speciation in rice grain: comparing a range of common cultivars grown in contaminated sites across Bangladesh, China, and India. Environ Sci Technol 43:8381-8386

Norton GJ, Islam MR, Deacon CM, Zhao FJ, Stroud JL, McGrath SP, Islam S, Jahiruddin M, Feldmann J, Price AH, Meharg AA (2009b) Identification of low inorganic and total grain arsenic rice cultivars from Bangladesh. Environ Sci Technol 43:6070-6075

Norton GJ, Pinson SRM, Alexander J, Mckay S, Hansen H, Duan GL, Islam MR, Islam S, Stroud JL, Zhao FJ, McGrath SP, Zhu YG, Lahner B, Yakubova E, Guerinot ML, Tarpley L, Eizenga GC, Salt DE, Meharg AA, Price AH (2012) Variation in grain arsenic assessed in a diverse panel of rice (Oryza sativa) grown in multiple sites. New Phytol 193:650-664 
Pillai TR, Yan WG, Agrama HA, James WD, Ibrahim AMH, McClung AM, Gentry TJ, Loeppert RH (2010) Total grain-arsenic and arsenic-species concentrations in diverse rice cultivars under flooded conditions. Crop Sci 50:2065-2075

Signes-Pastor AJ, Mitra K, Sarkhel S, Hobbes M, Burlo F, De Groot WT, CarbonellBarrachina AA (2008) Arsenic speciation in food and estimation of the dietary intake of inorganic arsenic in a rural village of west Bengal, India. J Agr Food Chem 56:9469-9474

Styblo M, Del Razo LM, Vega L, Germolec DR, LeCluyse EL, Hamilton GA, Reed W, Wang C, Cullen WR, Thomas D (2000) Comparative toxicity of trivalent and pentavalent inorganic and methylated arsenicals in rat and human cells. Arch Toxicol 74:289-299

Takahashi Y, Minamikawa R, Hattori KH, Kurishima K, Kihou N, Yuita K (2004) Arsenic behavior in paddy fields during the cycle of flooded and nonflooded periods. Environ Sci Technol 38:1038-1044

Uraguchi S, Mori S, Kuramata M, Kawasaki A, Arao T, Ishikawa S (2009) Root-toshoot $\mathrm{Cd}$ translocation via the xylem is the major process determining shoot and grain cadmium accumulation in rice. J Exp Bot 60:2677-2688

Williams PN, Price AH, Raab A, Hossain SA, Feldmann J, Meharg AA (2005) Variation in arsenic speciation and concentration in paddy rice related to dietary exposure. Environ Sci Technol 39:5531-5540

Wu C, Ye ZH, Shu WS, Zhu YG, Wong MH (2011) Arsenic accumulation and speciation in rice are affected by root aeration and variation of genotypes. J Exp Bot 62:2889-2898

Yamaji N, Ma JF (2009) A transporter at the node responsible for intervascular transfer of silicon in rice. Plant Cell 21:2878-2883

Zhang J, Zhu YG, Zeng DL, Cheng WD, Qian Q, Duan GL (2008) Mapping quantitative trait loci associated with arsenic accumulation in rice (Oryza sativa). New Phytol 177:350-355

doi:10.1186/1939-8433-6-3

Cite this article as: Kuramata et al:: Genetic diversity of arsenic accumulation in rice and QTL analysis of methylated arsenic in rice grains. Rice 2013 6:3.

\section{Submit your manuscript to a SpringerOpen ${ }^{\circ}$ journal and benefit from:}

- Convenient online submission

- Rigorous peer review

- Immediate publication on acceptance

- Open access: articles freely available online

- High visibility within the field

- Retaining the copyright to your article

Submit your next manuscript at $>$ springeropen.com 